\section{Airway obstruction during anaesthesia for anterior cervical cord decompression}

To the Editor:

A 73-yr-old man was admitted to our hospital with cervical cord compression at the level of $\mathrm{C}_{4}-\mathrm{C}_{5}$ and $\mathrm{C}_{6}-\mathrm{C}_{7}$. Three hours after induction of anaesthesia for anterior cervical cord decompression, an increase in airway pressure suddenly occurred. Causative factors such as inadequate depth of anaesthesia and pulmonary pathology being excluded, the surgeon was asked to halt the procedure whilst the patient's airway problem was being dealth with. As he removed his retractor from the operative site the airway obstruction was suddenly relieved.

The surgeon used an anterior approach to the cervical spine which has been shown to be the safest ${ }^{1}$ and the surgical incision made here, in close proximity to the trachea, and the use of a retractor encourages tracheal compression. The retractor was in such a position that it probably compressed the trachea below the level of the distal end of the tracheal tube (TT). Other causes of airway obstruction include kinking of a TT that is in situ or deviation of the TT so that the bevel of the tube is intermittently applied to the side wall of the trachea or carina; occasionally herniation of a TT cuff could lead to obstruction.

Monitoring of airway pressure waveform and possibly gas flow throughout the respiratory cycle may assist anaesthetists in assessing the cause of airway obstruction. Obstruction of the airway will lead to a marked increase in initial rise of pressure during the inspiratory phase. Possible techniques of avoiding airway obstruction include insertion of an oesophageal bougie to increase the rigidity of the medial structures; use of an armoured, kink resistant TT with the tube inserted so that its tip lies just above the level of the carina which increases the rigidity of the larynx and trachea and places the bevel of the TT below the site of operation; or the use of a TT in which a Murphy's eye has been cut.

Surgeons and anaesthetists involved in operations performed on the cervical spine should be aware of the possible risk of pressure from surgical retraction causing airway obstruction but careful positioning of an armoured TT and meticulous surgical technique should reduce the risk.

Pierre Beaulieu MSc MD

Caroline Davies MB BS FRCA

Department of Anaesthesia

St. Bartholomew's Hospital
West Smithfield

London EC1A 7BE

United Kingdom

REFERENCE

1 Symon L, Thomas DGT, Clark K. Neurosurgery. In: Rob C, Smith R (Eds.). Operative Surgery, 4th ed., Philadelphia: J.B. Lippincott, 1989: 381-8.

\section{Subcutaneous emphysema and laparoscopic cholecystectomy}

\section{To the Editor:}

We believe that there may be a factor more important than the subcutaneous tracking of $\mathrm{CO}_{2}$ to explain the hypercarbia described by Dr. Pearce ${ }^{1}$ which his patient developed. The Bain circuit is one in which partial rebreathing of exhaled gases occurs. ${ }^{2}$ The extent of rebreathing is increased with increased minute ventilation and decreased with increased fresh gas flow. ${ }^{2}$

In the Clinical Report, prior to insufflation of the peritoneal cavity with $\mathrm{CO}_{2}$, the ventilation and fresh gas flow were sufficient to maintain the $\mathrm{PETCO}_{2}$ at $32 \mathrm{mmHg}$. These same variables, when confronted by the added $\mathrm{CO}_{2}$ load after insufflation of the abdomen, permitted the PETCO ${ }_{2}$ to rise to $45 \mathrm{mmHg}$. Dr. Pearce increased the minute ventilation by $122 \%$ (from $600 \mathrm{ml} \times 12 \mathrm{bpm}$ to $800 \mathrm{ml} \times 20 \mathrm{bpm}$ ) but only increased the fresh gas flow $33 \%$ (from $4.5 \mathrm{~L} \cdot \mathrm{min}^{-1}$ to $6 \mathrm{~L} \cdot \mathrm{min}^{-1}$ ). The $\mathrm{PeTCO}_{2}$ increased to $60 \mathrm{mmHg}$ during the next $50 \mathrm{~min}$ when $\mathrm{N}_{2} \mathrm{O}$ was discontinued and $\mathrm{O}_{2}$ was continued at $5 \mathrm{~L} \cdot \mathrm{min}^{-1}$. With further "rapid manual ventilation" the $\mathrm{PETCO}_{2}$ climbed to $85 \mathrm{mmHg}$ and the $\mathrm{PaCO}_{2}$ was measured at $100 \mathrm{mmHg}$. Probably this further increased $\mathrm{PETCO}_{2}$ was caused by additional minute ventilation from "rapid manual ventilation" in the face of the reduced fresh gas flow at $5 \mathrm{~L} \cdot \mathrm{min}^{-1}$.

In the discussion of this case, Dr. Pearce recommended an increase of ventilation as an intervention in hypercarbia. He comments that, in retrospect, the fresh gas flow should have been higher to be more effective. Certainly, for an increased $\mathrm{CO}_{2}$ load, an increase in minute ventilation is required to maintain normocarbia. However, when the Bain circuit is used, any increase in minute ventilation must be counteracted by an increase in fresh gas flow to ensure that rebreathing is minimized.

Subcutaneous $\mathrm{CO}_{2}$ could contribute to an added $\mathrm{CO}_{2}$ load in the immediate postoperative period and result in prolonged return of $\mathrm{PETCO}_{2}$ to normal values because of slower absorption from the subcutaneous sites. However, we believe that the combination of increased minute 
ventilation in the face of insufficient fresh gas flows with the Bain circuit (resulting in profound rebreathing) is a more plausible explanation for the exceptional $\mathrm{PETCO}_{2}$ described in this Clinical Report.

\section{B. Mezon MD FRCPC \\ N. Badner MD FRCPC \\ Department of Anaesthesia \\ University Hospital \\ London, Ontario N6A 5A5}

\section{REFERENCES}

1 Pearce DJ. Respiratory acidosis and subcutaneous emphysema during laparoscopic cholecystectomy. Can J Anaesth 1994; 41 314-6.

2 Andrews JJ. Anesthesia systems. In: Barash PG, Cullen BF, Stoelting RK (Eds.). Clinical Anesthesia. New York: Lippincott, 1989: 531-3.

\section{REPLY}

I thank Drs. Mezon and Badner for their thoughts on the case, but I don't think diminished gas flow in the face of increased minute volume explains the rapid hypercarbia. Firstly, within $15 \mathrm{~min}$ the $\mathrm{PETCO}_{2}$ increased from 32 to $45 \mathrm{~mm} \mathrm{Hg}$ without alteration of ventilation or fresh gas flow. Secondly, I have never seen a doubling of $\mathrm{PETCO}_{2}$ simply by increasing the minute volume without augmenting the fresh gas flow.

To test Drs. Mezon and Badner's hypothesis, I conducted a trial simulation during an anaesthetic given to a stable 79yr-old woman undergoing mastectomy. She was given a general anaesthetic with tracheal intubation and mechanical ventilation delivering nitrous oxide, oxygen and Forane. Afier increasing her ventilator settings from respiratory rate 10/tidal volume 800 $\mathrm{ml}$ to $\mathrm{RR} 20 / \mathrm{VT} 1000 \mathrm{ml}$ and decreasing $\mathrm{N}_{2} \mathrm{O} / \mathrm{O}_{2}$ from $4 / 2$ $L \cdot \min ^{-1}$ to $3 / 1.5 \mathrm{~L} \cdot \mathrm{min}^{-1}$ for $20 \mathrm{~min}$, her PETCO $\mathrm{O}_{2}$ only changed from 36 to $38 \mathrm{mmHg}$. This does not appear to be a large effect and does not explain the dramatic hypercarbia changes seen in the case I presented.

However, I do agree that increasing fresh gas flow would assist in the elimination of $\mathrm{CO}_{2}$ and this may be more important when using the Bain circuit.

D.J. Pearce MD CCFP(EM)

Alexandra Marine and General Hospital

Goderich, Ontario N7A 1W5

\section{The diving reflex: bradycardia during cold ocular irrigation}

To the Editor:

We read with interest the informative article by Drs. Arndt and Stock regarding the concern of bradycardia during cold ocular irrigation under general anaesthesia. ${ }^{1}$ We wish to share our experiences regarding this issue. As Arndt describes, classically the diving reflex causes bradycardia without hypotension during the application of cold irrigants to the distribution of the ophthalmic division of the fifth cranial nerve. ${ }^{2}$ Bradycardia is then mediated through the vagus nerve. In man, this trigeminal-brainstem vagal function is initiated by application of $0-20^{\circ} \mathrm{C}$ cold saline to the face. ${ }^{2,3}$ Both the cornea and the iris are supplied by myelinated afferent nerve fibres from the ophthalmic division of the fifth cranial nerve. One would expect that if a cold irrigant solution were applied to the iris, in isolation of the cornea, the diving reflex would occur. This, however, does not appear to be the case.

At our institution a "topical" anaesthetic technique is currently being used for cataract surgery. In this technique the patient's cornea is anaesthetized topically with a solution of $0.75 \%$ bupivacaine. This blocks all afferent input to the trigeminal nerve from the corneal surface. During surgery, cold irrigant solution $\left(4^{\circ} \mathrm{C}\right)$ is used to irrigate the anterior chamber. During the irrigation the iris afferent supply remains unblocked and thus is being excited by the cold irrigant. One might expect the diving reflex to occur. However, since the original article by Drs. Arndt and Stock (June, 1993) 300 patients have been managed in this way with no noted episode of bradycardia or arrhythmias. The only adverse effect noted is that the patient describes slight ocular discomfort during cold irrigation. We are currently prospectively documenting the patient's pulse rate immediately before and during cold irrigation.

Although the diving reflex is an apparent theoretical concern during cold irrigation in a "topical" anaesthetic technique, it does not appear to be of clinical significance. This leads us to question as to whether the case of bradycardia during anaesthesia as described by Arndt and Stock was a tue example of the diving reflex. One might conclude that while the "watertight drape was placed around the left eye and the surgeon began to irrigate the eye liberally with sterile, room temperature $\left(19.7^{\circ} \mathrm{C}\right)$, normal saline," pressure was applied to the periocular structure thus initiating an oculocardiac reflex rather than a diving reflex.

\section{D.L. Zimmerman MD \\ R.G. Loken MD \\ R.C. Hamilton MB \\ Department of Anaesthesia \\ Foothills Hospital \\ 1403-29 Street NW \\ Calgary, Alberta T2N 2T9}

\section{REFERENCES}

1 Arndt GA, Stock MC. Bradycardia during cold ocular irrigation under general anaesthesia: an example 